\title{
Performance of PET Post-Consume Bottle Fiber into a Concrete Matrix
}

\author{
F.J. Baldenebro-Lopez ${ }^{1,2}$, C.D. Gomez-Esparza ${ }^{1}$, J.H. Castorena-Gonzalez ${ }^{2}$, J.I. Velazquez-Dimas ${ }^{2}$, W. \\ Antunez-Flores ${ }^{1}$, J.E. Ledezma-Sillas ${ }^{1}$, R. Martinez-Sanchez ${ }^{1}$, J.M. Herrera-Ramirez ${ }^{1}$ \\ 1. Centro de Investigación en Materiales Avanzados (CIMAV), Laboratorio Nacional de \\ Nanotecnología, Miguel de Cervantes No.120, Chihuahua, Chih., México C.P. 1109 \\ 2. Universidad Autónoma de Sinaloa, Facultad de Ingeniería Mochis, Fuente de Poseidón y Prol. Angel \\ Flores S/N, Los Mochis, Sinaloa, México, C.P. 81223
}

In the cementitious matrix composites reinforced with fibers, the matrix is the first to fail since it has the smaller deformation in the fracture. With this type of matrix, the behavior of the matrix-fiber interface has a great importance on the final mechanical behavior of the composite [1]. The fibers are mainly introduced to improve toughness and strength of the brittle matrix, which is why the performance of these depends on their ability to interact with the mechanism that governs the toughness [2], generating several mechanisms of energy absorption controlled by the behavior of the interface between the fiber and the matrix. In turn, this results firstly in the interface failure, the crack deviation and the pull-out of the fibers before the matrix failure, achieving an increase in the composite toughness.

The pull-out test is of great interest for fiber reinforced concrete because it simulates the configuration of a fiber surrounded by a crack in the matrix; in such a way that, in this work the adherence of PET fibers to the concrete was investigated. In this test a part of the fiber was embedded into a concrete matrix and a tension force was applied to pull out the fiber. For embedded lengths longer than a critical value, the fiber will break. For lengths smaller than the critical length, the fiber will be pulled-out and the shear strength can be calculated by simple forces equilibrium. For obtaining the toughness of concrete beams, a three-point bending test was developed. During the test the evolution of the load and the displacement were registered. The concrete-fiber interface and the effect of the fiber pull-out were characterized by field emission scanning electron microscopy using a JEOL JSM-7401F microscope, operated at $5 \mathrm{kV}$ and $10 \mathrm{kV}$.

The toughness of ordinary concrete (OC) and ( $0.25 \mathrm{wt} . \%)$ fiber reinforced concrete (FRC) were acquired and compared. The load-deflection curves of figure 1 indicate that the addition of fibers increased the flexural resistance from $4.87 \mathrm{kN}$ for OC to $8.08 \mathrm{kN}$ for FRC; in the case of the toughness, the increment was from $3.26 \mathrm{~J}$ for $\mathrm{OC}$ to $69.65 \mathrm{~J}$ for FRC. Figure 2 shows the pull-out curve of the fiber-concrete tested; a load of $141.76 \mathrm{~N}$ was reached and no apparent fiber loosening with respect to the matrix was observed. The insets in figure 2 present the pull-out test setup and the aspect of a fiber after being tested.

Figure 3 shows the damage generated by the pulling effect of the PET fiber embedded in concrete, which suggests that there was a good adherence between both materials. Figure 4 shows the interface between a fiber and concrete, it was observed that the adherence between the matrix and the reinforcement is caused by a mechanical effect generated by the friction at the interface, which prevents the fiber pull-out in the concrete matrix [3]. 


\section{References:}

[1] AT Horne, IG Richardson and RMD Brydson, Cement and Concrete Research 37 (2007), p. 1613.

[2] C Yao, M Nakashima, Earthquake Engineering and Engineering Vibration 11 (2012), p. 11.

[3] The authors acknowledge funding through project PROFAPI 2012/40 and support from CONACYTRed Temática de Nanociencias y Nanotecnología.

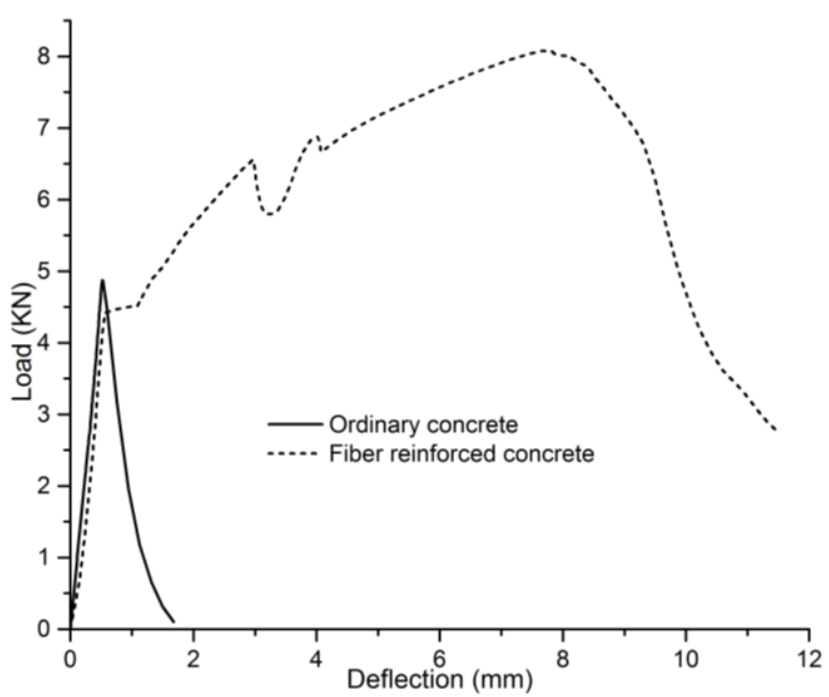

Figure 1. Load-deflection plot of the ordinary concrete and fiber reinforced concrete.

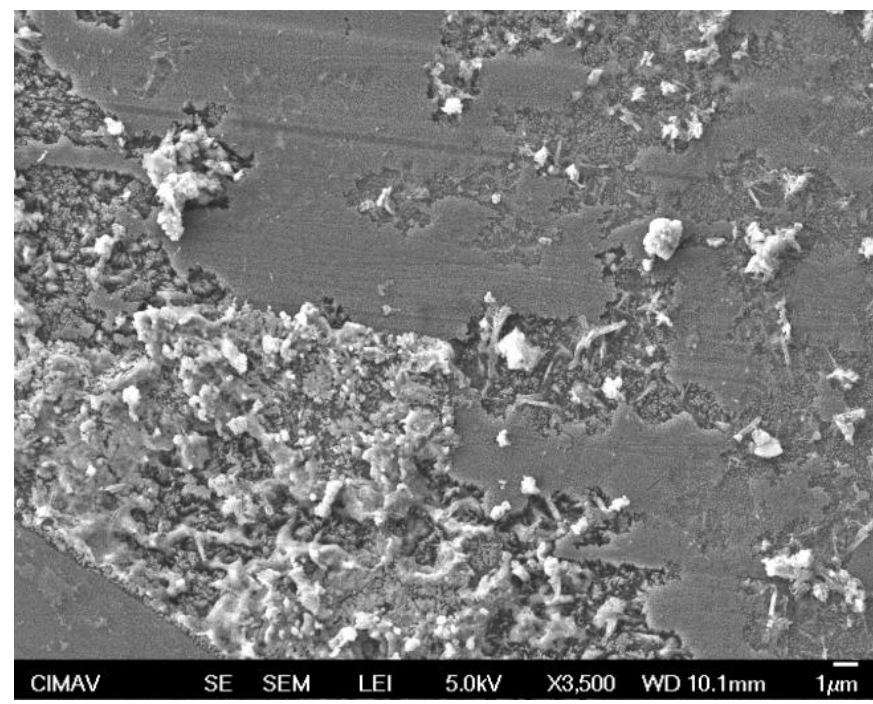

Figure 3. SEM micrograph of PET damage generated by the stripping effect of the concrete matrix.

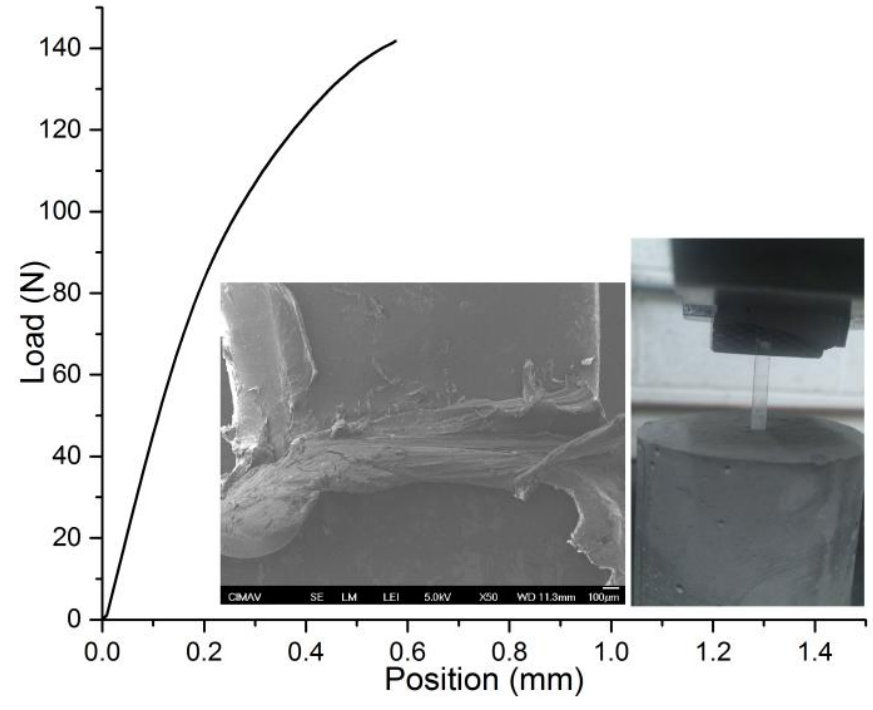

Figure 2. Diagram of the pull-out test in fiberconcrete.

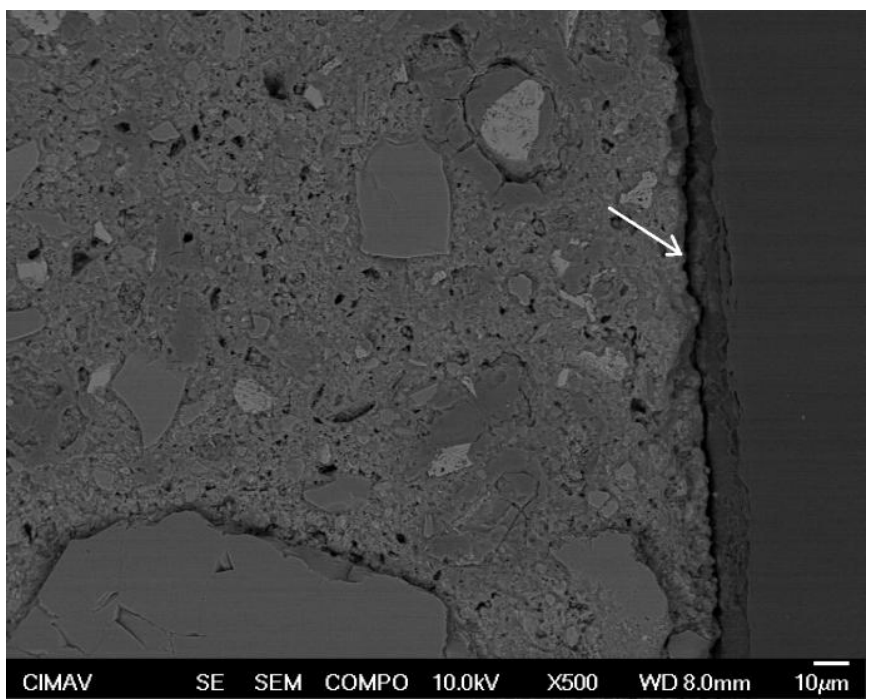

Figure 4. Interface of the concrete-PET fiber. 